\title{
Predictors of Survival in Neurometastatic Merkel Cell Carcinoma
}

\section{Citation}

Harary, Maya. 2019. Predictors of Survival in Neurometastatic Merkel Cell Carcinoma. Doctoral dissertation, Harvard Medical School.

\section{Permanent link}

http://nrs.harvard.edu/urn-3:HUL.InstRepos:41971523

\section{Terms of Use}

This article was downloaded from Harvard University's DASH repository, and is made available under the terms and conditions applicable to Other Posted Material, as set forth at http:// nrs.harvard.edu/urn-3:HUL.InstRepos:dash.current.terms-of-use\#LAA

\section{Share Your Story}

The Harvard community has made this article openly available.

Please share how this access benefits you. Submit a story.

\section{Accessibility}




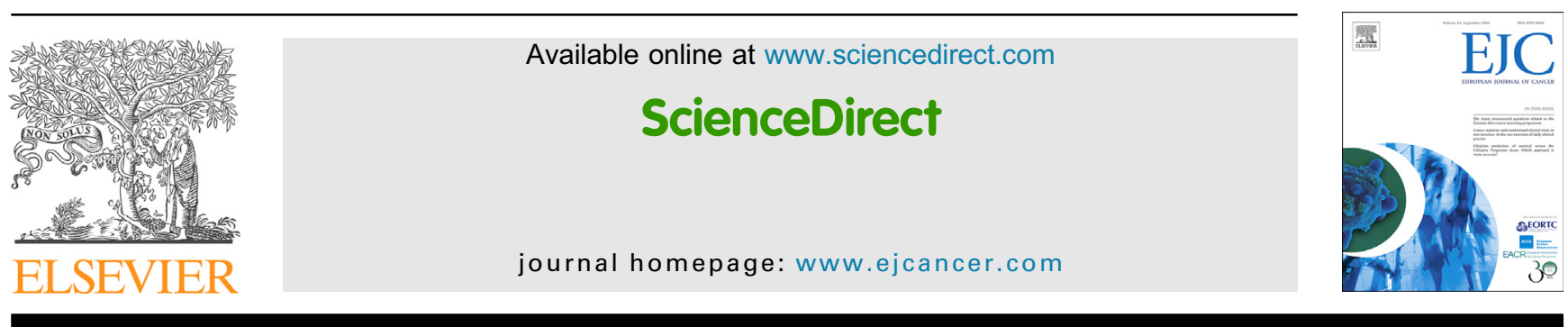

\title{
Original Research
}

\section{Predictors of survival in neurometastatic Merkel cell carcinoma ${ }^{\text {it }}$}

\author{
Maya Harary ${ }^{a}$, Vasileios K. Kavouridis ${ }^{\text {a, }}$ Manisha Thakuria ${ }^{\text {b, } *, 1}$, \\ Timothy R. Smith ${ }^{\mathrm{a}, 1}$
}

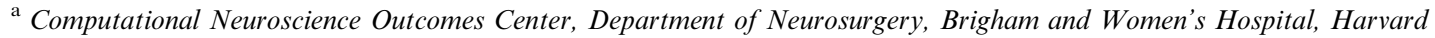
Medical School, Boston, MA, USA

${ }^{\mathrm{b}}$ Center for Cutaneous Oncology, Department of Dermatology, Dana-Farber/Brigham and Women's Cancer Center, Harvard Medical School, Boston, MA, USA
}

Received 29 April 2018; received in revised form 15 June 2018; accepted 2 July 2018

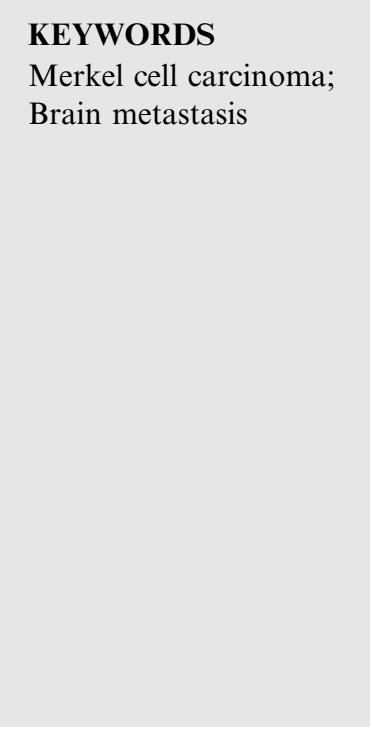

\begin{abstract}
Background: Merkel cell carcinoma (MCC) is a rare cutaneous malignancy of neuroendocrine origin, with about 30 cases of brain metastasis (BM) reported in the literature. Historically, the treatment of neurometastatic MCC has largely included chemotherapy and radiotherapy. The aim was to investigate predictors of overall survival (OS) in neurometastatic MCC.

Methods: In this retrospective study, we surveyed institutional databases and conducted a systematic review of the literature to identify cases reporting on management of distant MCC BM. A pooled survival analysis was performed on the institutional and literature cases to assess predictors of OS.

Results: Forty cases were included for analysis, describing operative [14] and non-operative [26] management. Median time to central nervous system involvement was 17.0-mos (interquartile range 10.5-26.5), and most patients had a single BM (62.5\%). Management of intracranial disease included radiotherapy $(82.5 \%)$, systemic therapy $(59.5 \%)$ and surgical resection (35\%). Operative management was associated with a lower intracranial burden of disease (BoD), but similar systemic BoD. Both neurosurgery (hazard ratio [HR] 0.18, 95\% confidence interval [CI]: 0.06-0.54, p = 0.002), having RT (HR 0.37, 95\% CI: 0.14:0.93, p = 0.04) and having a single BM (extensive intracranial BoD: HR 2.51, 95\% CI: 1.12-5.6, p = 0.03) conferred an OS benefit on risk-unadjusted analysis. Only, neurosurgical resection was an independent predictor of OS (HR 0.12, 95\% CI: 0.03-0.49, p = 0.003), controlling for age, BoD and radiotherapy.
\end{abstract}

\footnotetext{
Review board: Project completed under Partners Human Research Committee approval (Protocol \#2015P002352)

* Corresponding author: Center for Cutaneous Oncology, Department of Dermatology, Dana-Farber/Brigham and Women's Cancer Center, 221 Longwood Ave., Boston MA, 02115, USA.

E-mail address: mthakuria1@bwh.harvard.edu (M. Thakuria).

1 These authors contributed equally and share senior co-authorship.
} 
Conclusions: Resection of MCC BM may confer a survival benefit given appropriate patient selection. Prospective investigation of multimodal management of neurometastatic MCC is warranted, especially given the promise of new immunotherapy agents in treating MCC.

(c) 2018 Elsevier Ltd. All rights reserved.

\section{Introduction}

Merkel cell carcinoma (MCC), initially referred to as trabecular or neuroendocrine carcinoma of the skin, is a rare malignancy of neuroendocrine origin that was first described by C. Toker in 1972 [1]. The estimated incidence of MCC is approximately 0.79 new cases per 100,000 people per year, with significant increases in incidence over the past few decades [2,3]. Initial characterisation of the disease and its differentiation from other carcinomas were difficult due to its varied appearance on histology, but diagnosis has since become more standardised with the use of cytokeratin-20 (CK20) immune-histochemical staining, which is likely contributing to the observed increase in incidence $[4,5]$.

MCC most commonly presents with a cutaneous primary lesion [4]. In about $4 \%$ of cases, it presents as metastatic disease in the absence of a primary lesion $[4,6]$. The loco-regional management approach has included wide local excision of the primary skin lesion, followed by lymphadenectomy or sentinel lymph node biopsy, and regional radiotherapy (RT) $[7,8]$. Though recently falling out of favour, chemotherapy (CT) alongside RT has historically been the predominant approach in patients who develop metastatic disease [7].

Given the relative low incidence of this disease, there have only been about 30 cases of MCC brain metastases (BM) reported in the literature. There remains no consensus regarding the benefit of neurosurgical resection. In this article, we report on predictors of survival in patients with neurometastatic MCC based on 13 cases treated at our institutions and cases previously reported in the literature.

\section{Methods}

\subsection{Patient identification}

Brigham and Women's Hospital (BWH) and Massachusetts General Hospital (MGH) institutional databases were queried for patients with MCC, who had brain imaging of any modality (computed tomography or magnetic resonance imaging [MRI]) in the electronic medical record. To be included, patients needed to have a pathologically proven diagnosis of MCC based on pathology from the primary site, lymph node and/or another distant metastasis. Radiology reports for brain imaging of any modality were reviewed to identify patients with brain lesions. MRI reports and/or images were reviewed to assess number and location of BM. Diagnosis of the lesion as an MCC BM was based on pathologic confirmation in surgically treated patients and the absence of other concurrent oncologic diagnoses with neurometastatic potential. Patient demographics and clinical course were extracted by chart review under an intitutional review board-approved protocol.

Patient age is represented as age at time of initial MCC diagnosis. Patients with direct intracranial invasion from scalp primary MCC lesions, as opposed to distant metastases, were excluded. Intracranial metastatic burden of disease (BoD) was analysed in a dichotomous fashion, with patients categorised as having either a single $\mathrm{BM}$ or extensive burden ( $>1 \mathrm{BM}$ and/ or leptomeningeal disease). Systemic BoD was treated similarly with patients categorised as either having the central nervous system (CNS) as the sole metastatic site or extensive burden (non-draining lymph node involvement, solid organ and/or bone metastases).

\subsection{Literature search}

A systematic review of the literature was conducted according to PRISMA guidelines (Supplemental Fig. 1). Briefly, English-language studies describing a case(s) of MCC BMs by distant metastatic spread and reporting on treatment strategy and survival outcomes were included. Reviews or editorial articles were excluded. Abstract and title screening, as well as subsequent fulltext screening and data extraction were done by two reviewers, and disagreements were resolved by discussion. Four non-operative cases from the literature did not report the patients' intracranial and systemic metastatic BoD; these were imputed as extensive burden for the purpose of analysis.

\subsection{Statistical analysis}

Statistical analysis was conducted on $\mathrm{R}$ (version 3.4.0). Student's t-test and Pearson chi-squared statistic were used to compare continuous and categorical variables, respectively. A Mann-Whitney test was used for nonparametric comparisons. A Kaplan-Meier curve was computed with a log-rank statistic. Cox-proportional hazard regression was used to analyse survival outcomes between the groups. Variables with a $\mathrm{p}<0.25$ on 
Table 1

Institutional case series.

\begin{tabular}{|c|c|c|c|c|c|c|c|c|c|}
\hline $\begin{array}{l}\text { Management } \\
\text { of BM }\end{array}$ & Age/sex & Primary lesion & $\begin{array}{l}\text { Systemic therapy } \\
\text { before CNS spread }^{\text {a }}\end{array}$ & $\begin{array}{l}\text { Systemic BoD at } \\
\text { time of CNS } \\
\text { spread }\end{array}$ & $\begin{array}{l}\text { Time to } \\
\text { CNS spread } \\
(\mathrm{mt})\end{array}$ & BM location & $\begin{array}{l}\text { Brain-directed } \\
\text { RT }\end{array}$ & $\begin{array}{l}\text { Systemic } \\
\text { therapy } \\
\text { after CNS } \\
\text { spread }\end{array}$ & $\begin{array}{l}\text { Survival } \\
\text { from CNS } \\
\text { spread }(\mathrm{mt})\end{array}$ \\
\hline \multirow[t]{6}{*}{ Non-operative } & $39 \mathrm{~F}$ & Unk. & $\mathrm{CT}>\mathrm{TT}>\mathrm{CT}$ & LN, liver, spleen & 16 & $\begin{array}{l}\text { R Meckel's cave, } \\
\text { cerebellum, L pons }\end{array}$ & WBRT & IT & 2 \\
\hline & $74 \mathrm{M}$ & Parotid & $\begin{array}{l}\mathrm{CT}+\mathrm{RT}>\mathrm{IT}+\mathrm{TT}>\mathrm{CT} \\
+\mathrm{HT}>\mathrm{CT}+\mathrm{IT}\end{array}$ & $\mathrm{LN}$ & 26 & $\mathrm{~L}$ frontal & - & IT & 6 \\
\hline & $81 \mathrm{M}$ & Forehead & RT & LN, ilium & 24 & $\mathrm{R}$ parietal, $\mathrm{L}$ temporal & SRS & - & 29 \\
\hline & $65 \mathrm{M}$ & Unk. & $\mathrm{CT}$ & - & 11 & Leptomeninges & WBRT & $\begin{array}{l}\text { Intrathecal } \\
\mathrm{CT}\end{array}$ & 5 \\
\hline & $67 \mathrm{M}$ & Parotid & $\mathrm{CT}+\mathrm{RT}>\mathrm{CT}$ & $\mathrm{LN}$ & 12 & $\mathrm{R}$ parietal & WBRT & - & 38 \\
\hline & $70 \mathrm{M}$ & Scalp & $\mathrm{RT}>\mathrm{CT}+\mathrm{RT}>\mathrm{HT}$ & Liver & 50 & L frontal, leptomeninges & WBRT & - & 0.9 \\
\hline \multirow[t]{7}{*}{ Operative } & $75 \mathrm{M}$ & Forehead & $\mathrm{CT}+\mathrm{RT}$ & $\mathrm{LN}$ & 44 & Cerebellum & - & - & 0.5 \\
\hline & $76 \mathrm{~F}$ & Breast & $\mathrm{CT}+\mathrm{RT}$ & - & 11 & $\mathrm{R}$ parietal & WBRT & - & 45 \\
\hline & $66 \mathrm{~F}$ & Unk. & $\mathrm{CT}$ & LN, femur & 13 & Cerebellum & $\mathrm{SRS}>\mathrm{WBRT}$ & $\mathrm{IT}>\mathrm{TT}$ & 28 \\
\hline & $59 \mathrm{M}$ & Leg & $\mathrm{RT}>\mathrm{CT}$ & $\mathrm{LN}$, rib & 35 & Cerebellum & $\mathrm{SRS}>\mathrm{WBRT}$ & - & 18 \\
\hline & $60 \mathrm{~F}$ & Unk. & $\mathrm{CT}+\mathrm{RT}$ & $\mathrm{LN}$ & 2 & $\begin{array}{l}{ }^{\mathrm{b}} \mathrm{L} \text { parietal, } \mathrm{L} \text { frontal, } \\
\mathrm{R} \text { temporal, } \mathrm{R} \text { occipital, } \\
\mathrm{R} \text { frontal, R parietal, } \\
\text { cerebellum }[2]\end{array}$ & WBRT & IT & 15 \\
\hline & $81 \mathrm{~F}$ & Leg & $\mathrm{CT}$ & LN & 21 & $\mathrm{R}$ frontal & SRS & IT & 10 \\
\hline & $81 \mathrm{M}$ & Chest & $\mathrm{RT}$ & - & 24 & $\mathrm{~L}$ cingulate & SRS & IT & 10 \\
\hline
\end{tabular}

Survival in bold-type represents patients who were still alive at time of reporting.

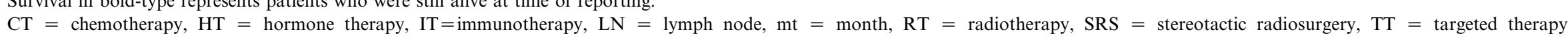
Unk. = unknown, WBRT $=$ whole-brain radiotherapy. " $>$ " represents sequence of treatment progression, $\mathrm{BM}=$ brain metastasis, BoD $=$ burden of disease, $\mathrm{CNS}=$ central nervous system.

${ }^{a}$ Radiotherapy (RT) here refers to RT directed at draining lymph nodes.

b This patient underwent resection of two symptomatic metastases (L parietal and frontal), she had WBRT before surgery but no adjuvant RT. 
bivariate analysis and those associated with higher likelihood of neurosurgical resection were included in the multivariable analysis. A p-value $<0.05$ was considered significant.

\section{Results}

\subsection{Case series}

A total of 193 unique patients were treated at BWH or MGH between 2004 and 2017 for MCC and had brain imaging of any modality. Screening of radiology reports identified a total of 13 cases of MCC BM secondary to distant metastatic spread (Table 1). In all but one patient, new neurological symptoms were the trigger for brain imaging. In one patient, BM was detected incidentally in the setting of re-staging before enrolment in a trial. In all patients in whom the primary lesion site was known (i.e. did not present just with lymph node involvement or distant metastases), wide local excision was performed with sentinel lymph node biopsy when indicated. Six of the patients had a history of other malignancies, including squamous cell carcinoma of the skin $(\mathrm{n}=2)$, basal cell carcinoma $(\mathrm{n}=4)$, melanoma in situ $(\mathrm{n}=2)$, lung adenocarcinoma $(\mathrm{n}=1)$, prostate carcinoma $(\mathrm{n}=1)$ and urothelial carcinoma $(\mathrm{n}=1)$. One patient was immunosuppressed at time of MCC diagnosis for a prior renal transplant.

Before CNS involvement, patients were treated with a range of therapies including RT to draining lymph node, systemic CT, immunotherapy, hormone therapy with octreotide and/or targeted therapy agents. The most commonly used CT regimen was carboplatin and etoposide combination therapy. Immunotherapy agents used included pembrolizumab, avelumab and ipilimumab. Targeted therapy agents included pazopanib, cabozantinib and other agents under clinical investigation.

In seven cases, the BM was managed operatively, and the remaining six were treated non-operatively. Most patients had brain-directed RT with either stereotactic radiosurgery (SRS) and/or whole-brain radiotherapy (WBRT), either in place of surgery or as adjuvant therapy. New systemic therapy was initiated in seven patients following CNS involvement and included immunotherapy, and in one case, intrathecal CT.

\subsection{Literature search}

A systematic search of the literature resulted in 105 unique articles about MCC (Supplemental Fig. 1). Subsequent screening identified 23 included articles, published between 1983 and 2017 reporting on the treatment and survival of a total of 27 patients with MCC BM due to distant metastatic spread (Supplemental Table 1). In all cases, where the primary lesion was known, a surgical excision was performed. In all reports that described the patient's clinical presentation leading up to the diagnosis of CNS involvement (20/27), patients had new neurologic symptoms to trigger brain imaging. In twenty cases, the MCC BM were non-operatively managed with either systemic or intrathecal CT, or brain-directed RT.

\subsection{Baseline patient characteristics}

A total of 40 cases were included in the pooled analysis (Table 2). As mentioned, all patients with a known primary lesion $(n=26,65 \%)$ were treated with a wide surgical excision. Of these, only $57.7 \%$ received adjuvant RT to the primary site and draining lymph nodes. A majority of those patients presenting with nodal disease in the absence of a primary lesion received RT to involved lymph nodes $(64.3 \%)$.

Median time from initial MCC diagnosis to CNS involvement was 17.0 months (IQR 10.5-26.5). At time of CNS involvement, most patients had extracranial metastatic involvement (57.5\%), including non-regional lymph nodes, visceral organs and bone. Most patients $(62.5 \%)$ had a single BM at time of CNS involvement, and $12.5 \%$ had leptomeningeal spread.

Table 2

Baseline patient characteristics $(\mathrm{N}=40)$.

\begin{tabular}{ll}
\hline Age at diagnosis, yr (mean \pm SD) & $65.1 \pm 10.1$ \\
Sex, $\mathrm{n}$ female $(\%)$ & $11(27.5)$ \\
Location of primary, n (\%) & $12(42.5)$ \\
Head and neck & $4(10.0)$ \\
Torso & $2(5.0)$ \\
Upper extremities & $3(7.5)$ \\
Lower extremities & $14(35.0)$ \\
Unknown & $23(57.5)$ \\
Chemotherapy before CNS spread, n (\%) & $24(60.0)$ \\
Regional RT to primary site and/or & \\
LN disease, n (\%) & $17.0(10.5-26.5)$ \\
Time to CNS involvement, mts (median, IQR) & \\
Systemic BoD, n (\%) & $17(42.5)$ \\
Only CNS & $23(57.5)$ \\
Extensive & \\
Intracranial BoD, n (\%) & $25(62.5)$ \\
Single BM & $15(37.5)$ \\
Extensive & $14(35.0)$ \\
Resection of $\geq 1$ BM, n (\%) & \\
Brain-directed RT, n (\%) & $7(17.5)$ \\
None & $12(30.0)$ \\
SRS & $26(65.0)$ \\
WBRT & \\
Systemic therapy after CNS spread, n (\%) & $15(40.5)$ \\
None & $11(29.7)$ \\
Chemotherapy & $6(16.2)$ \\
Immunotherapy & $7(18.9)$ \\
Other &
\end{tabular}

$\mathrm{BoD}=$ burden of disease, $\mathrm{LN}=$ lymph node, $\mathrm{RT}=$ radiotherapy, $\mathrm{SRS}=$ stereotactic radiosurgery, $\mathrm{WBRT}=$ whole-brain radiation therapy, $\mathrm{CNS}=$ central nervous system, $\mathrm{BM}=$ brain metastasis. Some patients were treated with $>1$ RT or systemic treatment modality after CNS spread.

a "Other" includes intrathecal CT or intracavitary BCNU wafers (Gliadel). 


\subsection{Management of CNS disease}

Management of CNS disease included RT (82.5\%), systemic therapy $(57.9 \%)$ and surgical resection $(35 \%)$. RT most commonly consisted of WBRT (68.4\%). Of patients receiving $\mathrm{RT}, 7$ patients $(22.6 \%)$ received both SRS and WBRT in their treatment course. Surgical resection of the BM was done in 14 cases $(35 \%)$. Patients undergoing neurosurgical resection were more likely to be female $(50 \%$ versus $15.4 \%, \mathrm{p}=0.02)$ and have limited intracranial $\mathrm{BoD}$ (i.e. a single $\mathrm{BM}, 92.9 \%$ versus $46.2 \% \mathrm{p}=0.004)$. The primary lesion in the nonoperative group most commonly localised to the head and neck region $(57.7 \%)$, whereas the patients in the operative group were more likely to present with advanced disease in the absence of a known primary lesion $(42.9 \%)$. These differences in location of the primary lesion were not significant.

\subsection{Predictors of overall survival}

Bivariate analysis demonstrated that having a single $\mathrm{BM}$, as opposed to more extensive intracranial disease, as well as undergoing surgical resection of BMs was associated with improved overall survival (OS, Table 3). Similarly, receiving any modality of brain-directed RT was also associated with improved OS. Patient demographics, location of primary tumour and treatment with systemic therapy were not predictive of OS. Median OS in patients undergoing neurosurgical intervention was 73 months $(95 \%$ CI $31-115)$, while that of the nonoperative group was 25 months $(95 \%$ CI $17-44)$, representing a statistically significant difference $(\mathrm{p}<0.001$, Fig. 1). On multivariable analysis, only surgical resection was an independent predictor of OS (HR 0.12, 95\% CI $0.03-0.49, \mathrm{p}=0.003$ ), controlling for age, sex, systemic and intracranial $\mathrm{BoD}$, prior therapy and therapy following CNS involvement.

\section{Discussion}

Neurometastatic MCC is a rare manifestation of a likewise uncommon malignancy. As such, there is a dearth of high-quality evidence to guide treatment decisions. In comparison with the algorithmic management of stage IV metastatic melanoma, practice guidelines for MCC patients with metastatic disease are ambiguous, suggesting a multidisciplinary discussion with consideration of surgical resection, RT and systemic therapy depending on the clinical status $[9,10]$.

Distant dissemination of MCC occurs in $40-50 \%$ of patients, of which an approximate $13 \%$ have CNS metastases [11-13]. Intracranial involvement may occur either directly, via transcalvarial invasion of a primary lesion on the head, or via distant metastatic spread. The earliest report of MCC BM was reported on two patients in 1983 by Wick et al. [14]. Neither received braindirected therapy, and the one patient with full survival information succumbed to the disease one month following CNS involvement. The following reports integrated brain-directed RT, most commonly WBRT, alongside systemic CT. It was only in 2001 when the first surgical management of MCC BM was reported by Ikawa et al. [15].

\subsection{Impact of neurosurgery on $O S$}

In this study, we performed a survival analysis in patients with MCC BM, pooling our institutional series with prior cases reported in the literature. Resection of MCC BM was an independent predictor of OS, controlling for age, BoD and adjuvant therapy. Though the estimated 5-year survival rates for stage IV MCC is around $14 \%$, despite advanced stage, the median survival in the operatively managed $\mathrm{BM}$ patients reported here was 73 months (95\% CI 31-115) [16,17]. Extensive intracranial burden was associated with shorter survival

Table 3

Predictors of survival in MCC BM patients

\begin{tabular}{|c|c|c|c|c|c|c|}
\hline & \multicolumn{3}{|c|}{ Bivariate Cox regression } & \multicolumn{3}{|c|}{ Multivariable Cox regression } \\
\hline & HR & $95 \% \mathrm{CI}$ & p-value & HR & $95 \% \mathrm{CI}$ & p-value \\
\hline Surgical resection (ref non-op) & 0.18 & $0.06-0.54$ & 0.002 & 0.12 & $0.03-0.49$ & 0.003 \\
\hline Age & 1.00 & $0.96-1.03$ & 0.86 & & & \\
\hline Sex (ref male) & 0.62 & $0.25-1.54$ & 0.30 & 2.02 & $0.66-6.20$ & 0.22 \\
\hline \multicolumn{7}{|l|}{ Location of primary } \\
\hline Head and neck & Ref & & & & & \\
\hline Torso & 0.68 & $0.15-3.03$ & 0.61 & & & \\
\hline Upper extremities & 0.36 & $0.04-3.05$ & 0.35 & & & \\
\hline Lower extremities & 0.00 & NA & 1 & & & \\
\hline Unknown & 0.99 & $0.42-2.34$ & 0.97 & & & \\
\hline Intracranial BoD (ref single BM) & 2.51 & $1.12-5.6$ & 0.03 & 1.10 & $0.43-2.78$ & 0.85 \\
\hline Systemic BoD (ref only CNS) & 1.69 & $0.73-3.90$ & 0.22 & 1.17 & $0.44-3.11$ & 0.75 \\
\hline Therapy before CNS involvement (ref none) & 0.77 & $0.31-1.94$ & 0.58 & & & \\
\hline Systemic therapy after CNS involvement (ref none) & 1.52 & $0.65-3.57$ & 0.33 & & & \\
\hline Brain-directed RT (ref none) & 0.37 & $0.14-0.93$ & 0.04 & 0.40 & $0.14-1.14$ & 0.09 \\
\hline
\end{tabular}

$\mathrm{BM}=$ brain metastasis, $\mathrm{BoD}=$ burden of disease, $\mathrm{CNS}=$ central nervous system, $\mathrm{RT}=$ radiotherapy, $\mathrm{CI}=$ confidence interval, $\mathrm{HR}$, hazard ratio, $\mathrm{MCC}=$ Merkel cell carcinoma. $\mathrm{p}$-values in bold-type represent statistical significance $(\mathrm{p}<0.05)$. 


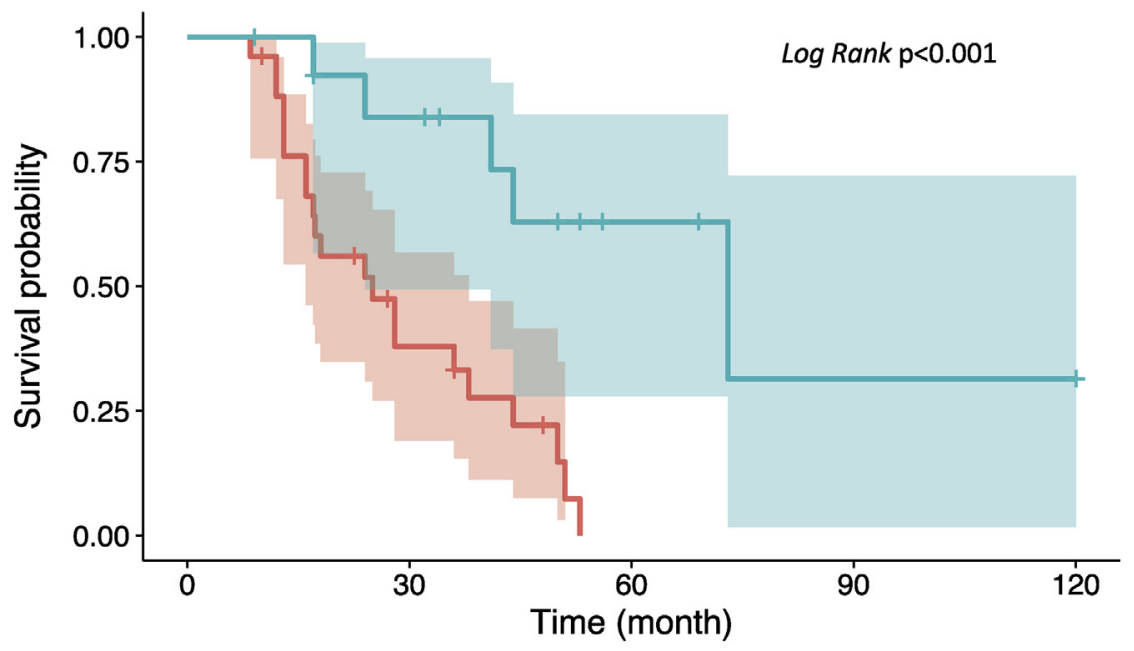

Number at risk

$\begin{array}{rccccr}\text { Non-operative } & 26 & 8 & 0 & 0 & 0 \\ \text { Operative } & 14 & 10 & 3 & 1 & 1 \\ & & & \\ \text { Strata }+ \text { Non-operative + Operative } & \end{array}$

Fig. 1. Kaplan-Meier curve for operative versus non-operative management of brain metastasis. Error bands represent $95 \%$ confidence interval.

on bivariate analysis, but not on multivariable analysis. This is likely explained by the fact that intracranial BoD is a key factor in patient selection for surgery. In other words, there is likely an interaction between lower intracranial burden and operative management, both of which contribute to improved survival. In the reported cohort, neuroimaging was primarily done in the setting of new neurologic symptoms which may suggest a role for CNS imaging in asymptomatic patients with stage IV disease, similar to advanced melanoma, which may allow for earlier intervention. Guidelines for BM management support surgical intervention in suitable patients on the basis of significant evidence of improved local control and extended survival [18-23]. The results of the present study suggest that these recommendations may also be applicable in cases of neurometastatic MCC.

\subsection{Role of adjuvant therapy}

There has been no prospective study to date examining the efficacy of RT specifically in the management of MCC BM. Nevertheless, there is evidence to suggest that MCC is a radio-sensitive tumour, with several studies demonstrating improved local recurrence and OS for adjuvant RT following resection of the primary lesion in stage I-III MCC [24-28]. Iyer et al. [29] reported on the use of single-fraction RT for visceral, lymph node, skin and bone MCC metastases and found that $94 \%$ of metastatic foci showed some response, and complete response was seen in $53 \%$ of foci. Nevertheless, a survival benefit of RT in the management of stage IV MCC is still under debate [16]. In our cohort, braindirected RT was not an independent predictor of OS. It is important to note, however, that given sample size limitations and the lack of detail regarding RT modality in some literature reports, we were unable to analyse the OS impact of SRS and WBRT individually. It is quite possible that, similar to evidence seen in the treatment of other BMs, SRS is superior to WBRT for MCC BM.

Operative patients were more likely to receive adjuvant SRS than the non-operative group. To an extent, the receipt of WBRT as opposed to SRS is likely associated with intracranial disease burden. The control of intracranial disease provided by BM resection may have allowed for an avoidance of or delay in WBRT until post-operative progression. This may protect patients from the known cognitive sequelae of WBRT [30,31].

With regards to adjuvant systemic therapy, about half of the cases in the literature received CT. Operative patients treated at our institutions received immunotherapy and/or targeted therapy as a part of clinical investigation. While used broadly in the included population, CT has largely grown out of favour both due to disappointing effects on OS and the associated drug toxicities $[7,29,32,33]$. More recently, immunotherapy, specifically inhibitors of the programmed cell death protein-1/ programmed cell death protein ligand-1 (PD-1/PDL-1) pathway, has shown particular promise for the treatment of advanced MCC [34,35]. Unfortunately, there were not 
enough patients in this study receiving immunotherapy to evaluate the effect of this treatment modality on survival in BM patients. While there are several ongoing trials investigating the use of immunotherapy for advanced MCC (NCT02267603, NCT03071406, NCT02584829, NCT03304639), they largely exclude patients with active CNS disease. Neurosurgical intervention and/or RT may be appropriate in suitable patients to allow for intracranial disease control, potentially making these patients trial candidates. It is important to note, however, that, drawing a corollary from emerging evidence in the treatment of advanced melanoma, radiation-induced immunogenicity may increase rates of radio-necrosis in patients receiving concurrent immunotherapy [36]. Further investigation of the safety and efficacy of combination therapy in intracranial disease control and OS in neurometastatic MCC is warranted.

\subsection{CNS involvement via direct spread}

Though MCC most commonly invades the CNS by distant spread via a haematogenous route, there have been reports of direct CNS extension from a head primary lesion, where the tumour invades through the calvarium, skull base or oral mucosa [37-40]. Barkdull et al. [38] reported one case where there was a CNS metastatic focus immediately below the overlying skin lesion in the absence of overt skull involvement. The authors proposed a mechanism involving spread along small emissary veins that communicate with diploic veins of the skull. Perineural spread has also been suggested [41]. Surgical intervention in cases of CNS involvement via direct extension is inherently different to cases of distant metastatic spread, and to our knowledge, has not been reported in the literature.

\subsection{Limitations}

This study is limited by the constraints inherent to a retrospective study design and the small sample size. The cases used in the pooled analysis span a time period of over 30 years and therefore represent large heterogeneity in treatment regimens as the field's understanding of this pathology gradually developed. Nevertheless, this is the first study to report on more than a handful of cases of neurometastatic MCC and to investigate the predictors of survival in neurometastatic MCC.

\section{Conclusions}

Neurosurgical resection was associated with a survival benefit for patients with neurometastatic MCC in this study. As always, oncologists and neurosurgeons need to assess the appropriateness of surgical intervention in context of the overall patient status and in accordance with patients' goals. Prospective studies are warranted, especially to evaluate the benefit of combination therapy with surgery, adjuvant RT and/or immunotherapy in MCC patients with neurometastatic disease.

\section{Conflict of interest statement}

The authors have no conflict of interest to declare.

\section{Appendix A. Supplementary data}

Supplementary data related to this article can be found at https://doi.org/10.1016/j.ejca.2018.07.002.

\section{References}

[1] Toker C. Trabecular carcinoma of the skin. Arch Dermatol 1972; 105(1):107-10.

[2] Fitzgerald TL, Dennis S, Kachare SD, Vohra NA, Wong JH, Zervos EE. Dramatic increase in the incidence and mortality from Merkel cell carcinoma in the United States. Am Surg 2015;81(8): 802-6.

[3] Stang A, Becker JC, Nghiem P, Ferlay J. The association between geographic location and incidence of Merkel cell carcinoma in comparison to melanoma: an international assessment. Eur J Cancer 2018;94:47-60.

[4] Coggshall K, Tello TL, North JP, Yu SS. Merkel cell carcinoma: an update and review: pathogenesis, diagnosis, and staging. J Am Acad Dermatol 2018;78(3):433-42.

[5] Plaza JA, Suster S. The Toker tumor: spectrum of morphologic features in primary neuroendocrine carcinomas of the skin (Merkel cell carcinoma). Ann Diagn Pathol 2006;10(6):376-85.

[6] Zhao M, Meng MB. Merkel cell carcinoma with lymph node metastasis in the absence of a primary site: case report and literature review. Oncol Lett 2012;4(6):1329-34.

[7] Tello TL, Coggshall K, Yom SS, Yu SS. Merkel cell carcinoma: an update and review: current and future therapy. J Am Acad Dermatol 2018;78(3):445-54.

[8] Sridharan V, Muralidhar V, Margalit DN, Tishler RB, DeCaprio JA, Thakuria M, et al. Merkel cell carcinoma: a population analysis on survival. J Natl Compr Canc Netw 2016; 14(10): 1247-57.

[9] Bichakjian C, Olencki T, Aasi A, Alam M, Andersen J, Blitzvlau R, et al. NCCN clinical practice guidelines in oncology for Merkel cell carcinoma (ver I). National Comprehensive Cancer Network; 2017.

[10] Lebbe C, Becker JC, Grob JJ, Malvehy J, Del Marmol V, Pehamberger H, et al. Diagnosis and treatment of Merkel Cell Carcinoma. European consensus-based interdisciplinary guideline. Eur J Cancer 2015;51(16):2396-403.

[11] Kouzmina M, Koljonen V, Leikola J, Bohling T, Lantto E. Frequency and locations of systemic metastases in Merkel cell carcinoma by imaging. Acta Radiol Open 2017;6(3). 2058460117700449.

[12] Shack R, Barton R. Is aggressive surgical management justified in the treatment of Merkel cell carcinoma? Plast Reconstr Surg 1994;94(7):970-5.

[13] Wynne CJ, Kearsley JH. Merkel cell tumor. A chemosensitive skin cancer. Cancer 1988;62(1):28-31.

[14] Wick MR, Goellner JR, Scheithauer BW, Thomas 3rd JR, Sanchez NP, Schroeter AL. Primary neuroendocrine carcinomas of the skin (Merkel cell tumors). A clinical, histologic, and ultrastructural study of thirteen cases. Am J Clin Pathol 1983;79(1): $6-13$.

[15] Ikawa F, Kiya K, Uozumi T, Yuki K, Takeshita S, Hamasaki O, et al. Brain metastasis of Merkel cell carcinoma. Case report and review of the literature. Neurosurg Rev 1999;22(1):54-7. 
[16] Schadendorf D, Lebbe C, Zur Hausen A, Avril MF, Hariharan S, Bharmal M, et al. Merkel cell carcinoma: epidemiology, prognosis, therapy and unmet medical needs. Eur J Cancer 2017;71: $53-69$.

[17] Harms KL, Healy MA, Nghiem P, Sober AJ, Johnson TM, Bichakjian CK, et al. Analysis of prognostic factors from 9387 Merkel cell carcinoma cases forms the basis for the new 8th edition AJCC staging system. Ann Surg Oncol 2016;23(11):3564-71.

[18] Andrews DW, Scott CB, Sperduto PW, Flanders AE, Gaspar LE, Schell MC, et al. Whole brain radiation therapy with or without stereotactic radiosurgery boost for patients with one to three brain metastases: phase III results of the RTOG 9508 randomised trial. Lancet 2004;363(9422):1665-72.

[19] Nabros L, Portnow J, Ammirati M, Baehring J, Brem H, Butowski N, et al. NCCN clinical practice guidelines in oncology for central nervous system cancers (Version 1.2017). National Comprehensive Cancer Network; 2017.

[20] Kalkanis SN, Kondziolka D, Gaspar LE, Burri SH, Asher AL, Cobbs CS, et al. The role of surgical resection in the management of newly diagnosed brain metastases: a systematic review and evidencebased clinical practice guideline. J Neuro Oncol 2010;96:33-43.

[21] Kocher M, Soffietti R, Abacioglu U, Villa S, Fauchon F, Baumert BG, et al. Adjuvant whole-brain radiotherapy versus observation after radiosurgery or surgical resection of one to three cerebral metastases: results of the EORTC 22952-26001 study. J Clin Oncol 2011;29(2):134-41.

[22] Mintz A, Perry J, Spithoff K, Chambers A, Laperriere N. Management of single brain metastasis: a practice guideline. Curr Oncol 2007;14(4):131-43.

[23] Jagannathan J, Yen CP, Ray DK, Schlesinger D, Oskouian RJ, Pouratian N, et al. Gamma Knife radiosurgery to the surgical cavity following resection of brain metastases. J Neurosurg 2009; 111(3):431-8.

[24] Takagishi SR, Marx TE, Lewis C, Tarabadkar ES, Juhlin ID, Blom A, et al. Postoperative radiation therapy is associated with a reduced risk of local recurrence among low risk Merkel cell carcinomas of the head and neck. Adv Radiat Oncol 2016;1(4):244-51.

[25] Jouary T, Leyral C, Dreno B, Doussau A, Sassolas B, BeylotBarry $\mathrm{M}$, et al. Adjuvant prophylactic regional radiotherapy versus observation in stage I Merkel cell carcinoma: a multicentric prospective randomized study. Ann Oncol 2012;23(4):1074-80.

[26] Medina-Franco H, Urist MM, Fiveash J, Heslin MJ, Bland KI, Beenken SW. Multimodality treatment of Merkel cell carcinoma: case series and literature review of 1024 cases. Ann Surg Oncol 2001;8(3):204-8.

[27] Bhatia S, Storer BE, Iyer JG, Moshiri A, Parvathaneni U, Byrd D, et al. Adjuvant radiation therapy and chemotherapy in Merkel cell carcinoma: survival analyses of 6908 cases from the National Cancer Data Base. J Natl Cancer Inst 2016;108(9).

[28] Cimbak N, Barker CA. Short-course radiation therapy for Merkel cell carcinoma: relative effectiveness in a "Radiosensitive" tumor. Int J Radiat Oncol Biol Phys 2016;96(2).
[29] Iyer JG, Parvathaneni U, Gooley T, Miller NJ, Markowitz E, Blom A, et al. Single-fraction radiation therapy in patients with metastatic Merkel cell carcinoma. Cancer Med 2015;4(8): 1161-70.

[30] Brown PD, Jaeckle K, Ballman KV, Farace E, Cerhan JH, Anderson SK, et al. Effect of radiosurgery alone vs radiosurgery with whole brain radiation therapy on cognitive function in patients with 1 to 3 brain metastases: a randomized clinical trial. J Am Med Assoc 2016:316(4):401-9.

[31] McDuff SG, Taich ZJ, Lawson JD, Sanghvi P, Wong ET, Barker 2nd FG, et al. Neurocognitive assessment following whole brain radiation therapy and radiosurgery for patients with cerebral metastases. J Neurol Neurosurg Psychiatry 2013;84(12): 1384-91.

[32] Voog E, Biron P, Martin JP, Blay JY. Chemotherapy for patients with locally advanced or metastatic Merkel cell carcinoma. Cancer 1999;85(12):2589-95.

[33] Nghiem P, Kaufman HL, Bharmal M, Mahnke L, Phatak H, Becker JC. Systematic literature review of efficacy, safety and tolerability outcomes of chemotherapy regimens in patients with metastatic Merkel cell carcinoma. Future Oncol 2017;13(14): 1263-79.

[34] Nghiem PT, Bhatia S, Lipson EJ, Kudchadkar RR, Miller NJ, Annamalai L, et al. PD-1 Blockade with pembrolizumab in advanced merkel-cell carcinoma. N Engl J Med 2016;374(26): $2542-52$.

[35] Kaufman HL, Russell J, Hamid O, Bhatia S, Terheyden P, D'Angelo SP, et al. Avelumab in patients with chemotherapyrefractory metastatic Merkel cell carcinoma: a multicentre, single-group, open-label, phase 2 trial. Lancet Oncol 2016;17(10): 1374-85.

[36] Martin AM, Cagney DN, Catalano PJ, Alexander BM, Redig AJ, Schoenfeld JD, et al. Immunotherapy and symptomatic radiation necrosis in patients with brain metastases treated with stereotactic radiation. JAMA Oncol 2018.

[37] Wojak JC, Murali R. Primary neuroendocrine (Merkel cell) carcinoma presenting in the calvarium: case report. Neurosurgery 1990;26(1):137-9.

[38] Barkdull GC, Healy JF, Weisman RA. Intracranial spread of Merkel cell carcinoma through intact skull. Ann Otol Rhinol Laryngol 2004;113(9):683-7.

[39] Litofsky NS, Smith TW, Megerian CA. Merkel cell carcinoma of the external auditory canal invading the intracranial compartment. Am J Otolaryngol 1998;19(5):330-4.

[40] Inoue T, Shimono M, Takano N, Saito C, Tanaka Y. Merkel cell carcinoma of palatal mucosa in a young adult: immunohistochemical and ultrastructural features. Oral Oncol 1997;33(3): $226-9$.

[41] Chang DT, Mancuso AA, Riggs Jr CE, Mendenhall WM. Merkel cell carcinoma of the skin with leptomeningeal metastases. Am J Otolaryngol 2005;26(3):210-3. 